\section{Control of intraocular pressure after deep sclerectomy}

HA Khairy ${ }^{1,2}$, FD Green ${ }^{1}$, MK Nassar ${ }^{2}$ and A Azuara-Blanco ${ }^{1}$
${ }^{1}$ Department of Ophthalmology, Aberdeen Royal Infirmary, University of Aberdeen, UK

${ }^{2}$ Ophthalmology Department, Menoufyia University, Egypt

Correspondence: A AzuaraBlanco, Consultant Ophthalmologist, The Eye Clinic, Aberdeen Royal Infirmary, Aberdeen AB25 2ZN, UK

Tel: + 441224553217 ;

Fax: + 441224553213 .

E-mail: Aazblanco@

aol.com

Received: 10 October 2004 Accepted: 15 February 2005 Published online: 15 April 2005

\section{Abstract}

Aim To study the long-term outcome of deep sclerectomy in patients with open angle glaucoma.

Methods Prospective consecutive series of 43 eyes (38 patients) with medically uncontrolled open-angle glaucoma undergoing deep sclerectomy. All patients underwent clinical assessment before and after surgery at day 7 and at months $1,3,6,12,18,24,36$. Surgical success was considered if the patient's intraocular pressure (IOP) $<22 \mathrm{mmHg}$ and the IOP was lowered by more than $20 \%$ without the use of any medication. Kaplan-Meier survival curves were used to evaluate the success rate.

Results The mean follow-up time was 28.1 \pm 8.2 months. Mean IOP decreased significantly from a preoperative value of $24.6 \pm 5.5 \mathrm{mmHg}$ to a postoperative value of $18.5 \pm 4.6 \mathrm{mmHg}$ at 36 months $(P<0.001)$. Microperforation of TDM occurred in three cases $(7.0 \%)$ and ciliary body prolapse in one case $(2.3 \%)$ but did not prevent completion of the operation. Postoperatively, hyphaema was detected in one case and shallow anterior chamber in another case and both were treated conservatively. Bleb encapsulation with elevation of IOP occurred in two cases $(4.7 \%)$ and was treated with 5-fluorouracil subconjunctival injection. Goniopuncture with neodymium:YAG laser was performed in two cases $(4.7 \%)$. There were no other late complications with the exception of failure of the operation. On the life-table analysis the success rate at 12,24 , and 30 months were 61.4, 36.6 , and $18.9 \%$, respectively.

Conclusion Deep sclerectomy reduced the IOP temporarily while minimising the risk of postoperative complications commonly encountered with standard trabeculectomy. However, after long-term follow-up surgery failed to maintain a low IOP.
Eye (2006) 20, 336-340. doi:10.1038/sj.eye.6701878; published online 15 April 2005

Keywords: glaucoma; nonpenetrating trabeculectomy; deep sclerectomy

\section{Introduction}

Trabeculectomy is the most commonly performed surgery for glaucoma. ${ }^{1}$ However, even with numerous modifications proposed to the original trabeculectomy, the lack of a reproducible postoperative intraocular pressure (IOP) reduction and the potential complications had led several surgeons to try other alternatives. $^{2}$

Recently, there has been renewed interest in nonpenetrating glaucoma surgery. This procedure is designed to avoid full-thickness penetration into the anterior chamber. In theory this would minimise the risk of postoperative complications due to over-filtration and hypotony. ${ }^{3}$

A variety of nonpenetrating glaucoma procedures have been described in the literature with variable success. Sinusotomy ${ }^{4}$ and $\mathrm{Ab}$ externo trabeculectomy ${ }^{5}$ never became popular because they were difficult operations and the surgical results were not convincing. The other two procedures that have become most popular are deep sclerectomy and viscocanalostomy. ${ }^{5-9}$

Deep sclerectomy may be associated with the insertion of a collagen implant under the scleral flap. However, the collagen device is expensive, and it is unknown whether it is necessary to provide a satisfactory surgical outcome. The role of antimetabolites in deep sclerectomy is also uncertain.

In this study, we analysed the complications and the long-term outcome of a series of patients who underwent deep sclerectomy without collagen implant. 


\section{Methods}

In all, 43 eyes of 38 consecutive patients with medically uncontrolled open-angle glaucoma underwent deep sclerectomy. Inclusion criteria for the study were openangle glaucoma with uncontrolled IOP while receiving maximal medical treatment. Exclusion criteria were angle closure, previous intraocular or conjunctival eye surgery other than clear cornea phacoemulsification, previous laser treatment, and age less than 35 years.

Patients were informed of the risks, benefits, and alternative of surgery, and informed consent was obtained. Before surgery all patients underwent bestcorrected visual acuity assessment, applanation tonometry with Goldman tonometer, dilated fundus biomicroscopy, and gonioscopy.

After surgery the same examinations were performed at day 7 and at months 1, 3, 6, 12, 18, 24, 36, except for the gonioscopy that was performed at the examiner's direction. Postoperative complications were assessed as follows: hyphaema was considered to be present when erythrocytes were seen in the anterior chamber; hypotony was defined as a postoperative IOP $\leq 4 \mathrm{mmHg}$; anterior chamber depth was assessed in comparison with the fellow eye and anterior chamber inflammation was considered when flare or cells was seen by biomicroscopy. One experienced surgeon (FDG), using sub-Tenon's anaesthesia performed all surgeries.

A fornix base conjunctival flap was performed with careful haemostasis using wet field cautery. A one-third scleral thickness limbal-based flap measuring approximately $5 \times 5 \mathrm{~mm}^{2}$ was dissected up to $1 \mathrm{~mm}$ into clear cornea. Unroofing of the Schlemm's canal was performed by removal of another flap of the deep sclera measuring $4 \times 4 \mathrm{~mm}^{2}$, leaving a thin layer of deep sclera over the ciliary body and the choroid. At this stage, the aqueous was seen to percolate through the remaining trabeculo-descemet membrane. The superficial scleral flap was then repositioned and secured with 10-0 nylon sutures. The conjunctiva and the Tenon's capsule were closed with 8-0 vicryl sutures. The operation was performed without the use of antimetabolites, collagen implants or viscoelastics. When a macroperforation of the thin trabeculo-descemet membrane occurred, the surgery was converted into a standard trabeculectomy. Postoperatively, patients were treated with topical Betnesol-N four times a day for 3 weeks.

Surgical success was considered if the patient's IOP $<22 \mathrm{mmHg}$ and the IOP was lowered by more than $20 \%$ without the use of any medication.

If the IOP was elevated during the early postoperative period and the conjunctiva showed signs of increased vascularisation and scarring, subconjunctival injection of 5-fluorouracil (5-FU) was considered. Neodymium : YAG
(Nd:YAG) laser goniopuncture was considered at the site of surgery when filtration was insufficient, because of thick remaining trabeculo-descemet membrane as shown by gonioscopy, and the IOP was raised.

Results were analysed using Student's $t$-test for the comparison of means and Kaplan-Meier survival curves for the evaluation of long-term success rate.

\section{Results}

There were 22 males and 16 females involved in this series. All patients were white Caucasian. In all, 34 eyes $(79.1 \%)$ had primary open-angle glaucoma, five had lowtension glaucoma (11.6\%), and four had

pseudoexfoliation glaucoma (9.3\%) (Figure 1). The mean age of patients was $68.5 \pm 10.1$ years. The mean follow-up time was $28.1 \pm 8.2$ months.

Microperforation of TDM occurred in three cases $(7.0 \%)$ and ciliary body prolapse in one case $(2.3 \%)$ but did not prevent completion of the operation (Figure 2). Postoperatively, hyphaema was detected in one case and shallow anterior chamber in another case, and both were treated conservatively. There were no severe complications.

Bleb encapsulation and fibrosis with raised IOP occurred in two cases $(4.7 \%)$ and was treated with 5-FU subconjunctival injection. Goniopuncture with $\mathrm{Nd}$ : YAG laser was performed in two cases $(4.7 \%)$ but failed to reduce the pressure (Figure 2).

Mean IOP decreased significantly from a preoperative value of $24.6 \pm 5.5 \mathrm{mmHg}$ to a postoperative value of $16.6 \pm 4.4 \mathrm{mmHg}$ at 12 months $(P<0.001)$, $17.6 \pm 4.5 \mathrm{mmHg}$ at 24 months $(P<0.001)$, and $18.5 \pm 4.6 \mathrm{mmHg}$ at 36 months $(P<0.001)$ (Figure 3$)$. The mean number of medications reduced significantly from $2.1 \pm 0.9$ before surgery, to $0.7 \pm 1.1$ in the last postoperative visit $(P<0.001)$.

(POAG=Primary Open Angle Glaucoma, LTG=Low Tension Glaucoma, PXE=Pseudoexfoliative Glaucoma)

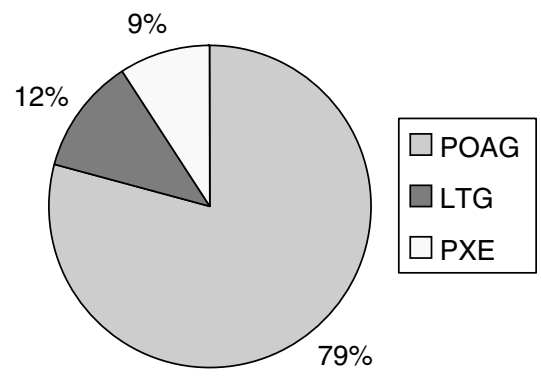

Figure 1 Distribution of type of glaucoma between patients (POAG = primary open-angle glaucoma; LTG = low-tension glaucoma; PXE = pseudoexfoliative glaucoma). 
(TDM=Trabeculo-Decemet Membrane, $\mathrm{AC}=$ Anterior Chamber, 5-FU=5- Flourouracil)

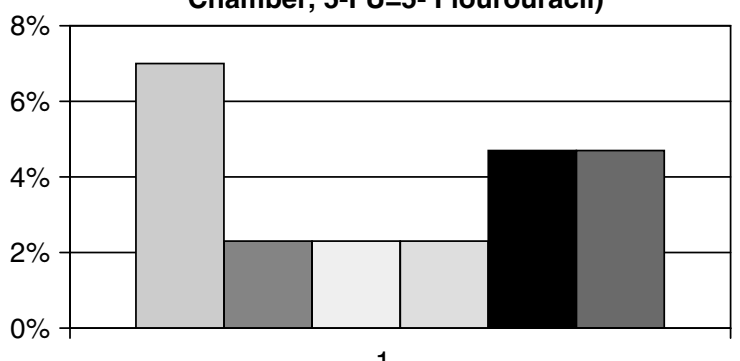

$\square$ Microperforation of TDM
$\square$ Ciliary body prolapse
$\square$ Hyphaema
$\square$ Shallow AC
$\square$ 5-FU
$\square$ Goniopuncture

Figure 2 Incidence of complications and additional procedures used after surgery (TDM=trabeculo-decemet membrane; 5$\mathrm{FU}=5$-flourouracil)

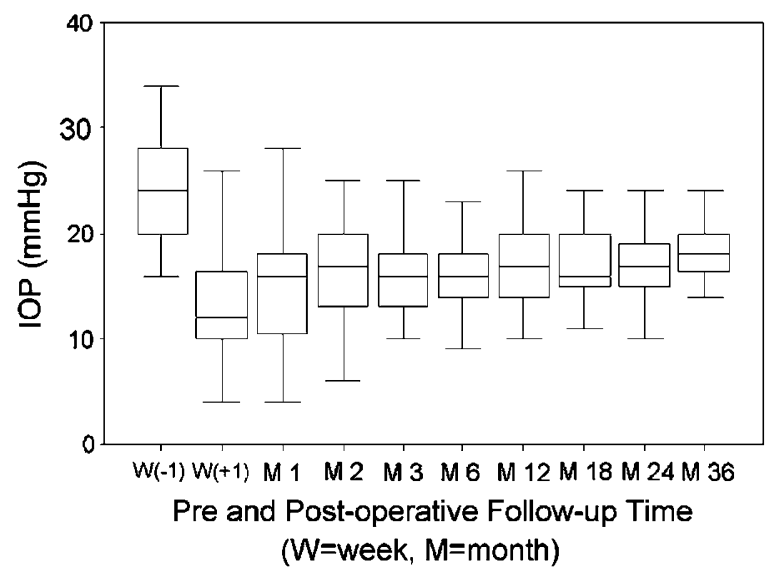

Figure 3 Mean intraocular pressure (IOP), pre- and postoperative $(\mathrm{mmHg})$.

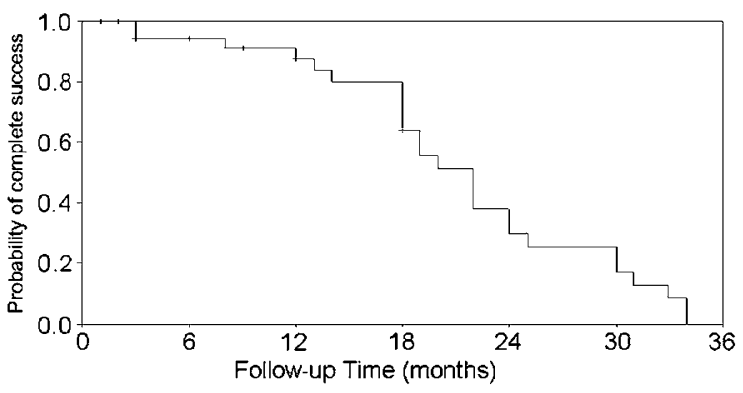

Figure 4 Kaplan-Meier analysis of success rate after nonpenetrating trabeculectomy. $X$-axis, follow-up time (months). $Y$-axis, probability of success.
On the life-table analysis, the complete success rate at 12,24 , and 30 months were $61.4,36.6$, and $18.9 \%$, respectively (Figure 4 ).

\section{Discussion}

Nonpenetrating trabeculectomy (NPT) has been developed in recent years to improve the safety of filtering procedures by avoiding full-thickness penetration into the anterior chamber. The goal of these procedures is to reduce IOP by enhancing the natural aqueous outflow while reducing the outflow resistance which is attributed mainly to the inner wall of Schlemm's canal and the adjacent trabeculum. ${ }^{10-14}$

Fyodorov $^{6}$ and Kozlov ${ }^{7}$ first described the procedure called deep sclerectomy. Several articles on deep sclerectomy describe surgical variants with collagen implants. ${ }^{8}$ Recently, antimetabolites have been associated with this type of surgery. In many published series postoperative goniopuncture is performed with a $\mathrm{Nd}$ : YAG laser which transform a nonpenetrating operation to a penetrating one. ${ }^{15-21}$

A few prospective studies comparing standard trabeculectomy and NPT have been published. In prospective randomised clinical trials El-Sayyad et al ${ }^{3}$ and Lachkar et $a^{22}$ randomly assigned patients to receive deep sclerectomy in one eye and trabeculectomy on the other eye. They did not find any statistical significant difference between the two procedures. Chiselita ${ }^{23}$ in a prospective randomised study comparing deep sclerectomy and trabeculectomy found significant differences in postoperative IOP levels at 18 months, with lower IOP level in the trabeculectomy group. In this study, the success rate was less than those published with trabeculectomy at all time points.

Fyodorov, ${ }^{6}$ Kozlov, ${ }^{7}$ and colleagues described a modification of deep sclerectomy using collagen implants (DSCI). Several authors reported a favourable outcome after DSCI. ${ }^{8,11,15,16}$ However, Demailly et al ${ }^{17}$ concluded that collagen devices did not seem to improve tonometric results after mid-term follow-up.

Mitomycin-C (MMC) and 5-FU are commonly used in high-risk filtration surgeries to improve the surgical success rate in these patients. Recent reports described the outcome of DSCI associated with intra- and postoperative use of antimetabolites. When 5-FU was used postoperatively, it appeared to improve only marginally the overall success rate. ${ }^{8,16,18} \mathrm{O}^{\prime}$ Brart et al ${ }^{24}$ reported the intraoperative use of antimetabolites in viscocanalostomy with $34 \%$ success rate in 12 months $(n=25)$. Ambresin et $a l^{25}$ reported that DSCI associated with 5-FU provided a better IOP control than trabeculectomy in a series of 20 patients undergoing deep sclerectomy in one eye and trabeculectomy in the fellow 
eye. Hamard $e a^{26}$ compared the success rates of DSCI vs deep sclerectomy with intraoperative 5-FU. The success rate was slightly higher $(66 \%)$ in the DSCI group compared to the 5-FU group (57\%).

Kozobolis et $a l^{27}$ in another study compared deep sclerectomy with and without the use of MMC in 90 patients after 3 years of follow-up. The use of MMC significantly reduced the IOP and increased the success rate of the procedure.

$\mathrm{Nd}$ : YAG laser goniopuncture has been used after deep sclerectomy when filtration through the trabeculodescemet membrane is considered to be insufficient. ${ }^{19}$ Mermoud et $a l^{15}$ studied the effect of $\mathrm{Nd}$ : YAG laser goniopuncture in 41 patients and reported long-term success rate of $68 \%$. Similar favourable results were reported by Sunaric-Megevand et al ${ }^{18}$ after mid-term follow-up of viscocanalostomy and by Wishart et al. ${ }^{28}$ However, to our knowledge, there are no randomised control trials evaluating the effect of YAG laser goniotomy in the control of IOP after NPT.

In this study, on the life-table analysis, the complete success rate at 12,24 , and 30 months were $61.4,36.6$, and $18.9 \%$, respectively. Overall, the IOP control in this series was suboptimal. Stricter criteria of surgical success such as IOP $15 \mathrm{mmHg}$ or reduction of at least $30 \%$ of IOP, increasingly used to describe outcomes of glaucoma surgeries, would be associated with lower success rate. Some studies have showed unfavourable results of NPT. 23,26,29,30 The correct depth of dissection achieved intraoperatively could be an important factor for the success of surgery. Rossier $e t a l^{31}$ and Vaudaux et $a l^{32}$ have shown that the remaining TDM provides a reproducible outflow resistance, and thus can account for the reproducibility of results in properly dissected deep sclerectomies. Results tend to improve with experience as has been shown by two recent studies. ${ }^{33,34}$ In this study, the IOP level in the first postoperative day was $15.6 \pm 4.4 \mathrm{mmHg}$ and $62.8 \%$ of cases achieved IOP less than $15 \mathrm{mmHg}$ and more than $30 \%$ reduction of the preoperative IOP level. In a recent report by Shaarawy et al, ${ }^{12}$ unfavourable results after DS show a mean IOP in the first day of $13.3 \mathrm{mmHg}$. It is unknown whether the use of adjunctive antimetabolites, viscoelastics, or collagen implants could have improved the long-term success of this procedure. Two cases with elevated IOP who developed fibrosis or encysted bleb were treated with subconjunctival injections of 5-FU. Nd:YAG laser goniopuncture was considered in two cases when filtration was insufficient, but not delivered in all patients who could receive this treatment. It is possible that with an increased number of laser goniopuncture treatments the surgical outcome could have improved. However, none of the above-mentioned procedures succeeded in lowering the IOP substantially.
In summary, deep sclerectomy reduced the IOP temporarily while minimising the risk of postoperative complications commonly encountered with standard trabeculectomy. However, surgery did not maintain a reduced IOP after long-term follow-up in many patients. The use of adjunctive antimetabolites, viscoelastics, or collagen implants could be considered to improve the long-term outcome of this operation.

\section{References}

1 Cairns JE. Trabeculectomy: preliminary report of a new method. Am J Ophthalmol 1968; 166: 673-681.

2 Mermoud A. Sinusotomy and deep sclerectomy. Eye 2000; 14: 531-535.

3 El-Sayyad F, Helal M, El-Kholify H, Khalil M, El-Maghraby A. Non-penetrating deep sclerectomy versus trabeculectomy in bilateral primary open angle glaucoma. Ophthalmology 2000; 107: 1671-1674.

4 Kranzov MM. Sinusotomy: foundation, results, prospects. Trans Am Ophthalmol Otolaryngol 1972; 76: 369-374.

5 Zimmermann TJ, Kooner KS, Ford VJ, Olander KW, Mandjekorn RM, Rawlings EF et al. Trabeculectomy vs nonpenetrating trabeculectomy: a retrospective study of two procedures in phakic patients with glaucoma. Ophthalmic Surg 1984; 12: 227-229.

6 Fyodorov SN. Non-penetrating deep sclerectomy in open angle glaucoma. Eye Microsurg 1989; 1: 52-55.

7 Kozlov VI, Bargov SN, Anisimova SY, Opsipov AV Mogilevtsev W. Non-penetrating deep sclerectomy with collagen. Eye Microsurg (in Russian) 1990; 3: 44-46.

8 Sanchez E, Schnyder CC, Mermoud A. Deep sclerectomy: results with and without collagen implant. Int Ophthalmol 1997; 20: 157-162.

9 Stegmann RC, Pienaar A, Miller D. Viscocanalostomy for open angle glaucoma in black african patients. J Cataract Refract Surg 1999; 25: 316-321.

10 Johnson DH, Johnson M. How does non-penetrating glaucoma surgery work? Aqueous outflow resistance and glaucoma surgery. J Glaucoma 2001; 10: 55-67.

11 Shaarawy T, Nguyen C, Schnyder C, Mermoud A. A comparative study between deep sclerectomy with and without collagen implant: long term follow up. $\mathrm{Br} \mathrm{J}$ Ophthalmol 2004; 88: 95-98.

12 Shaarawy T, Flammer J, Smits G, Mrmoud A. Low first postoperative day intraocular pressure as a positive prognostic indicator in deep sclerectomy. Br J Ophthalmol 2004; 88: 568-661.

13 Tan JCH, Hitchings RA. Non-penetrating glaucoma surgery: the state of play. Br J Ophthalmol 2001; 85: 234-237.

14 Shaarawy T, Mansouri K, Schnyder C, Ravinet E, Achache F, Mermoud A. Long term results of deep sclerectomy with collagen implant. J Cataract Refract Surg 2004; 30: 1225-1231.

15 Mermoud A, Schnyder CC. Nonpenetrating filtering surgery in glaucoma. Curr Opin Ophthamol 2000; 11: 151-157.

16 Karlen ME, Sanchez E, Schnyder CC, Sickenberg M, Mermoud A. Deep sclerectomy with collagen implants medium term results. Br J Ophthalmol 1999; 83: 6-11.

17 Demailly P, Lavat P, Kertz G, Jeanteur-Lunel MN. Nonpenetrating deep sclerectomy (NPDS) with or without collagen device $(\mathrm{CD})$ in primary open angle glaucoma: 
middle term retrospective study. Int Ophthalmol 1997; 20: 131-140.

18 Sunaric-Megevand G, Leuenberger PM. Results of viscocanalostomy for primary open angle glaucoma. Am J Ophthalmol 2001; 132: 221-228.

19 Mermoud A, Karlen ME, Schnyder CC, Sickenberg M, Chiou AGY, Hediguer SEA et al. Nd:YAG goniopuncture after deep sclerectomy with collagen implants. Ophthalmic Surg Lasers 1999; 30(2): 120-125.

20 Dahan E, Drusedau MUH. Non-penetrating filtration surgery for glaucoma: control by surgery only. J Cataract Refract Surg 2000; 26: 695-701.

21 Welsh NH, DeLange J, Wasserman P, Ziemba SL. The 'deroofing' of Schlemm's canal in patients with open angle glaucoma through placement of a collagen drainage device. Ophthalmic Surg Lasers 1998; 29: 216-226.

22 Lachkar Y, Hamard P. Nonpenetrating filtering surgery. Curr Opin Ophthalmol 2002; 13(2): 110-115.

23 Chiselita D. non-penetrating deep sclerectomy versus trabeculectomy in primary open angle glaucoma surgery. Eye 2001; 15: 197-201.

24 O'Brart DP, Shiew M, Edmunds B. A randomised, prospective study comparing trabeculectomy with viscocanalostomy with adjunctive antimetabolites usage for the management of open angle glaucoma uncontrolled by medical therapy. Br J Ophthalmol 2004; 86(8): 1012-1017.

25 Ambresin A, Shaarawy T, Mermoud A. Deep sclerectomy with collagen implant in one eye compared with trabeculectomy in the other eye of the same patient. J Glaucoma 2002; 11(3): 214-220.
26 Hamard P, Lachkar Y. Non penetrating filtering surgery, evolution and results. J Fr Ophthalmol 2002; 225(5): 527-536.

27 Kozobolis VP, Emmanouil V, Tzanakis N, Zacharopoulos I, Pallikaris IG. Primary deep sclerectomy versus deep sclerectomy with use of Mitomycin C in primary open angle glaucoma. J Glaucoma 2002; 11(4): 287-293.

28 Wishart PK, Wishart MS, Porooshani H. Viscocanalostomy and deep sclerectomy for the surgical treatment of glaucoma: a long-term follow up. Acta Ophthalmol Scand 2003; 81(4): 343-348.

29 Drusedau MU, von Wolff K, Bull H, von Baswisch B. Viscocanalostomy for primary open angle glaucoma: the Gross Pankow experience. J Cataract Refract Surg 2000; 2: 1367-1373.

30 Luke C, Dieltein TS, Jacobi PC, Konen W, Krieglestein GK. A prospective randomised trial of viscocanalostomy versus trabeculectomy in open angle glaucoma: a 1-year follow-up study. J Glaucoma 2002; 11: 294-299.

31 Rossier A, Uffer S, Mermoud A. Aqueous dynamics in experimental ab externo trabeculectomy. Ophthalmic Res 2000; 32: 165-171.

32 Vaudaux JUSMA. Aqueous after deep sclerectomy: in vitro study. Ophthalmic Practise 1999; 16: 204-209.

33 Gressel MG, Parrish PK, Heuer DK. Delayed nonexpulsive suprachoroidal haemorrhage. Arch Ophthalmol 1984; 102 1757-1760.

34 Jonescu-Cuypers C, Jacobi P, Konen W, Krieglestein GK. Primary viscocanalostomy versus trabeculectomy in white patients with open angle glaucoma. J Cataract Refract Surg 1999; 25: 254-258. 